\title{
Associations of the PON1 rs854560 polymorphism with plasma lipid levels: a meta-analysis
}

\author{
Zhi Luo ${ }^{1 \dagger}$, Shujin $\mathrm{Li}^{2 \dagger}$, Irfan Muhammad' ${ }^{1}$ Md Rezaul Karim³ and Yongyan Song ${ }^{4 *}$
}

\begin{abstract}
Background: Previous studies have investigated the associations of paraoxonase 1 (PON1) rs854560 polymorphism with plasma lipid levels, but the results are inconclusive. This meta-analysis aimed to clarify the associations of the rs854560 polymorphism with plasma lipid levels.

Methods: A comprehensive search of the literature was carried out by using the databases which include Medline, Google Scholar, Web of Science, Embase, Cochrane Library, China National Knowledge Infrastructure (CNKI), Wanfang and VIP database up till August 2018. The pooled standardized mean difference (SMD) with 95\% confidence interval (Cl) was used to assess the differences in lipid levels between the genotypes. Begg's funnel plots and Egger's test were used to examine the publication bias.

Results: A total of 41 studies (22,844 subjects) were identified for the associations of rs 854560 polymorphism with plasma lipid levels. The $\mathrm{M}$ carriers had lower levels of high-density lipoprotein Cholesterol (HDL-C) (SMD $=-0.15$, $95 \% \mathrm{Cl}=-0.23--0.07, P<0.01)$ and apolipoprotein $\mathrm{A}-\mathrm{I}(\mathrm{APOA} 1)(\mathrm{SMD}=-0.67,95 \% \mathrm{Cl}=-0.93--0.41, \mathrm{P}<0.01)$ than the non-carriers. Subgroup analysis by ethnicity revealed that the effect on HDL level was significant in Caucasians and the subjects of other ethnic origins. No publication bias was detected in this meta-analysis.
\end{abstract}

Conclusions: The meta-analysis suggests that the PON1 rs 854560 polymorphism is associated with a lower HDL-C level in Caucasians and subjects of other ethnic origins.

Keywords: Paraoxonase 1, Polymorphism, Lipids, Meta-analysis

\section{Introduction}

Coronary heart disease (CHD) is the leading cause of death in China and most of the developed countries [1]. While the interactions between genetic and environmental factors determine the pathogenesis of this disease, the report shows that dyslipidemia ranks as one of the most important risk factors accounting for at least 50\% of the population attributable risk [2]. Dyslipidemia is characterized by elevated levels of triglycerides (TG), total cholesterol (TC) and low-density lipoprotein cholesterol (LDL-C) as well as reduced levels of high-density lipoprotein cholesterol (HDL-C) in circulation. Over the

\footnotetext{
* Correspondence: songyongyan2014@foxmail.com

†Zhi Luo and Shujin Li contributed equally to this work.

${ }^{4}$ Department of Medical Biochemistry, and Nanchong Key Laboratory of Metabolic Drugs and Biological Products, North Sichuan Medical College, Nanchong 637000, People's Republic of China

Full list of author information is available at the end of the article
}

years, several investigations have been carried out on the genetic polymorphism/mutation that affects plasma lipid levels. The results, however, have been inconclusive primarily due to small sample size, ethnicity and difference in health conditions.

High-density lipoprotein (HDL) has been shown to play a critical role in reverse cholesterol transport (RCT) by eliciting cholesterol efflux from macrophage foam cells which prevents the progression of atherosclerotic lesions and induces the regression of existing plaques [3]. HDL-C has also been primarily associated with a protein, apolipoprotein A-I (APOA1) and the over-expression of APOA1 has equally been found to reduce atherosclerosis in mice. Along the same line, Paraoxonase 1 (PON1), an enzyme that hydrolyses aryl esters, phosphate esters and lactones has been shown to be associated with apoA-1 and HDL-C. According to Akbas et al. [4] HDL-associated

(c) The Author(s). 2018 Open Access This article is distributed under the terms of the Creative Commons Attribution 4.0 International License (http://creativecommons.org/licenses/by/4.0/), which permits unrestricted use, distribution, and reproduction in any medium, provided you give appropriate credit to the original author(s) and the source, provide a link to the Creative Commons license, and indicate if changes were made. The Creative Commons Public Domain Dedication waiver (http://creativecommons.org/publicdomain/zero/1.0/) applies to the data made available in this article, unless otherwise stated. 
PON1 is considered to be a major anti-atherosclerosis component of HDL, as it inhibits the oxidation of low-density lipoprotein (LDL) and promotes cholesterol efflux from macrophage foam cells [4-6].

The PON1 gene is located on the long arm of human chromosome 7 (7q21-22), containing 9 exons and 8 introns. Although some studies have demonstrated that PON1 gene rs 854560 polymorphism was significantly associated with CHD [7-9], whether this polymorphism is associated with dyslipidemia remains to be examined. A number of researches have investigated the associations of this polymorphism with plasma lipid levels, but the results were inconsistent and inconclusive. In some of these studies, the $\mathrm{M}$ allele of the rs 854560 polymorphism was reported to be significantly associated with higher levels of TG [10-12], TC [13, 14], LDL-C [13-15], and lower levels of HDL-C $[14,16]$ and apoA-I [16] while reports from other studies differ [17-21]. Hence, we conducted this meta-analysis to clarify the associations of the PON1 rs854560 polymorphism and the different plasma lipid levels by using a larger sample size and to put into consideration ethnicity and disease condition particularly atherosclerosis.

\section{Methods}

\section{Literature search}

A comprehensive search of the literature was carried out by using databases which include Medline, Google Scholar, Web of Science, Embase, Cochrane Library, China National Knowledge Infrastructure (CNKI), Wanfang and VIP database (up till August 2018). The terms "paraoxonase 1" or "PON1"; "polymorphism" or "mutation" or "variant" or
"SNP" or "rs854560" or "L55 M"; "blood lipid" or "serum lipid" or "lipids" were used for the search. The variables were limited to TG, TC, LDL-C, HDL-C and APOA1. The languages of the articles were limited to English and Chinese. All references cited in the included articles were reviewed to check for published works that were not indexed by Medline, Google Scholar, Web of Science, Embase, Cochrane Library, CNKI, Wanfang and VIP database.

\section{Inclusion criteria}

Studies that fulfill the following criteria were included: (1) studies in which the mean serum lipid values and standard deviations (SD) or standard errors (SE) by the rs854560 genotypes were available; (2) data reported on at least one of the five variables (TG, TC, LDL-C, HDL-C and APOA1); (3) data reported on fasting lipid variables; (4) pre-intervention baseline data that were used for interventional studies. Reports with incomplete data, studies based on pedigree data, case reports, review articles, abstracts and animal studies were excluded from the meta-analysis.

\section{Data extraction}

The studies that do not meet the inclusion criteria were excluded after being reviewed independently by two reviewers. All data were double-checked, compared after extraction and disagreements between reviewers were discussed and resolved. From each paper, the following information was collected: first author's name, year of publication, average age, country, ethnicity, gender, health condition and the mean of serum lipid levels and SD by genotypes. If a paper's data were unconvincing, we tried to contact the correspondent author

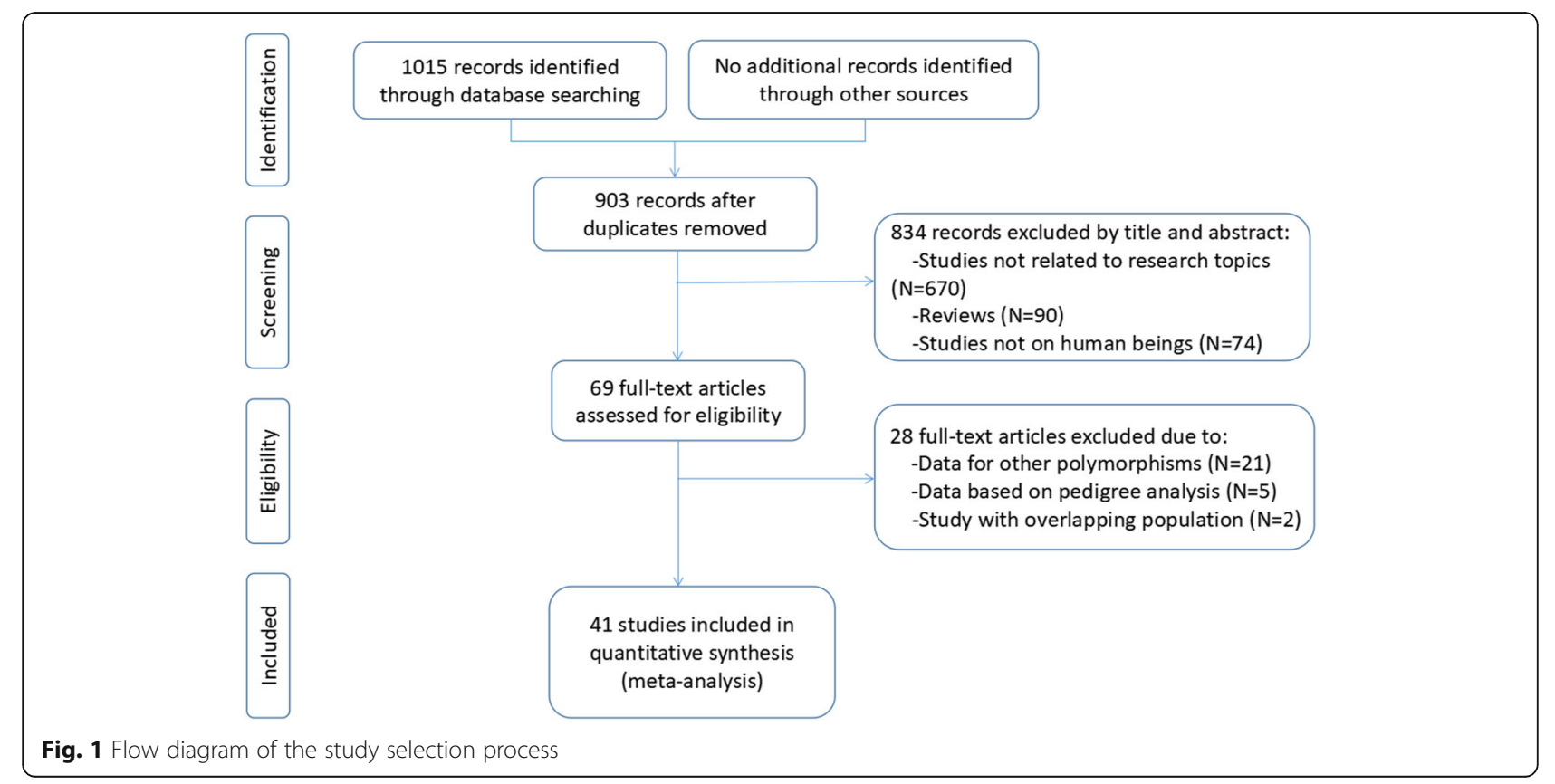


Table 1 Meta-analysis between the PON1 rs854560 polymorphism and plasma lipid levels

\begin{tabular}{|c|c|c|c|c|}
\hline Groups or subgroups & Comparisons (Subjects) & SMD $(95 \% \mathrm{Cl})$ & $P_{\text {Heterogeneity }}$ & $P_{S M D}$ \\
\hline \multicolumn{5}{|l|}{$\mathrm{TG}$} \\
\hline All & $42(12791)$ & $-0.01(-0.07-0.06)$ & $<0.01$ & 0.87 \\
\hline HWE & $33(9805)$ & $-0.02(-0.10-0.07)$ & $<0.01$ & 0.71 \\
\hline Male & $3(2920)$ & $-0.02(-0.09-0.05)$ & 0.42 & 0.58 \\
\hline Caucasian & $21(8278)$ & $-0.01(-0.09-0.07)$ & 0.01 & 0.81 \\
\hline Asian & $3(956)$ & $0.22(0.01-0.41)$ & 0.86 & 0.05 \\
\hline Other ethnic & $18(3557)$ & $-0.03(-0.18-0.11)$ & $<0.01$ & 0.64 \\
\hline $\mathrm{CHD}$ & $5(802)$ & $0.08(-0.20-0.35)$ & 0.01 & 0.59 \\
\hline T2DM & $3(693)$ & $0.38(-0.61-1.37)$ & 0.01 & 0.45 \\
\hline Healthy or control & $20(3268)$ & $-0.05(-0.19-0.08)$ & $<0.01$ & 0.45 \\
\hline Case-control & $6(5934)$ & $0.00(-0.05-0.06)$ & 0.45 & 0.90 \\
\hline \multicolumn{5}{|l|}{ TC } \\
\hline All & 45 (13715) & $-0.05(-0.11-0.02)$ & $<0.01$ & 0.15 \\
\hline HWE & $35(10411)$ & $-0.01(-0.06-0.04)$ & 0.29 & 0.68 \\
\hline Male & $5(3786)$ & $0.02(-0.04-0.09)$ & 0.51 & 0.47 \\
\hline Caucasian & $24(9202)$ & $0.01(-0.03-0.05)$ & 0.56 & 0.68 \\
\hline Asian & $3(956)$ & $0.03(-0.18-0.24)$ & 0.63 & 0.79 \\
\hline Other ethnic & $18(3557)$ & $-0.16(-0.33-0.01)$ & $<0.01$ & 0.07 \\
\hline $\mathrm{CHD}$ & $6(1593)$ & $0.04(-0.06-0.14)$ & 0.61 & 0.45 \\
\hline Healthy or control & $20(3305)$ & $-0.11(-0.26-0.03)$ & $<0.01$ & 0.12 \\
\hline Case-control & 7 (6252) & $0.01(-0.05-0.07)$ & 0.77 & 0.73 \\
\hline \multicolumn{5}{|l|}{ LDL-C } \\
\hline All & 48 (14319) & $0.00(-0.06-0.06)$ & $<0.01$ & 0.91 \\
\hline HWE & 35 (10632) & $0.03(-0.04-0.09)$ & 0.03 & 0.39 \\
\hline Male & $4(1002)$ & $0.17(-0.09-0.43)$ & 0.11 & 0.20 \\
\hline Caucasian & $24(9423)$ & $0.06(0.01-0.12)$ & 0.19 & 0.03 \\
\hline Asian & $5(1187)$ & $0.09(-0.17-0.34)$ & 0.32 & 0.49 \\
\hline Other ethnic & 19 (3709) & $-0.11(-0.23-0.01)$ & 0.01 & 0.08 \\
\hline $\mathrm{CHD}$ & $5(1387)$ & $0.09(-0.04-0.23)$ & 0.28 & 0.17 \\
\hline T2DM & $4(486)$ & $-0.09(-0.34-0.15)$ & 0.85 & 0.46 \\
\hline Healthy or control & $24(4919)$ & $0.01(-0.10-0.13)$ & $<0.01$ & 0.80 \\
\hline Case-control & $6(6364)$ & $0.05(-0.06-0.17)$ & 0.03 & 0.36 \\
\hline \multicolumn{5}{|l|}{$\mathrm{HDL}-\mathrm{C}$} \\
\hline All & 57 (19354) & $-0.15(-0.23--0.07)$ & $<0.01$ & $<0.01$ \\
\hline HWE & 41 (15157) & $-0.04(-0.07--0.01)$ & 0.99 & 0.05 \\
\hline Male & $4(2518)$ & $-0.06(-0.14-0.02)$ & 0.95 & 0.16 \\
\hline Female & $3(1714)$ & $0.01(-0.09-0.11)$ & 0.42 & 0.81 \\
\hline Caucasian & 41 (15269) & $-0.11(-0.20--0.02)$ & $<0.01$ & 0.02 \\
\hline Asian & $6(1405)$ & $-0.13(-0.39-0.13)$ & 0.18 & 0.33 \\
\hline Other ethnic & $11(2680)$ & $-0.32(-0.52--0.13)$ & $<0.01$ & $<0.01$ \\
\hline $\mathrm{CHD}$ & $7(2221)$ & $-0.03(-0.12-0.06)$ & 0.65 & 0.49 \\
\hline T2DM & $4(848)$ & $-0.35(-0.68--0.02)$ & 0.21 & 0.04 \\
\hline Healthy or control & 29 (8424) & $-0.11(-0.20--0.02)$ & $<0.01$ & 0.02 \\
\hline Case-control & 7 (6582) & $-0.41(-0.77--0.04)$ & $<0.01$ & 0.03 \\
\hline
\end{tabular}


Table 1 Meta-analysis between the PON1 rs854560 polymorphism and plasma lipid levels (Continued)

\begin{tabular}{|c|c|c|c|c|}
\hline Groups or subgroups & Comparisons (Subjects) & $\operatorname{SMD}(95 \% \mathrm{Cl})$ & $P_{\text {Heterogeneity }}$ & $P_{S M D}$ \\
\hline \multicolumn{5}{|l|}{ APOA1 } \\
\hline All & $22(13391)$ & $-0.67(-0.93--0.41)$ & $<0.01$ & $<0.01$ \\
\hline HWE & 20 (12398) & $-0.74(-1.03--0.46)$ & $<0.01$ & $<0.01$ \\
\hline Caucasian & $14(12212)$ & $-0.01(-0.05-0.03)$ & 0.78 & 0.66 \\
\hline Other ethnic & $6(808)$ & $-4.46(-6.69--2.24)$ & $<0.01$ & $<0.01$ \\
\hline Healthy or control & $9(4375)$ & $-0.13(-0.42-0.16)$ & $<0.01$ & 0.39 \\
\hline Case-control & $4(6891)$ & $-0.02(-0.10-0.05)$ & 0.15 & 0.56 \\
\hline
\end{tabular}

SMD standardized mean difference, 95\% Cl 95\% confidence interval, HWE Hardy-Weinberg equilibrium, TG triglyceride, TC total cholesterol, LDL-C low-density lipoprotein cholesterol, HDL-C high-density lipoprotein cholesterol, APOA1 apolipoprotein A-I, CHD coronary heart disease, T2DM type 2 diabetes mellitus

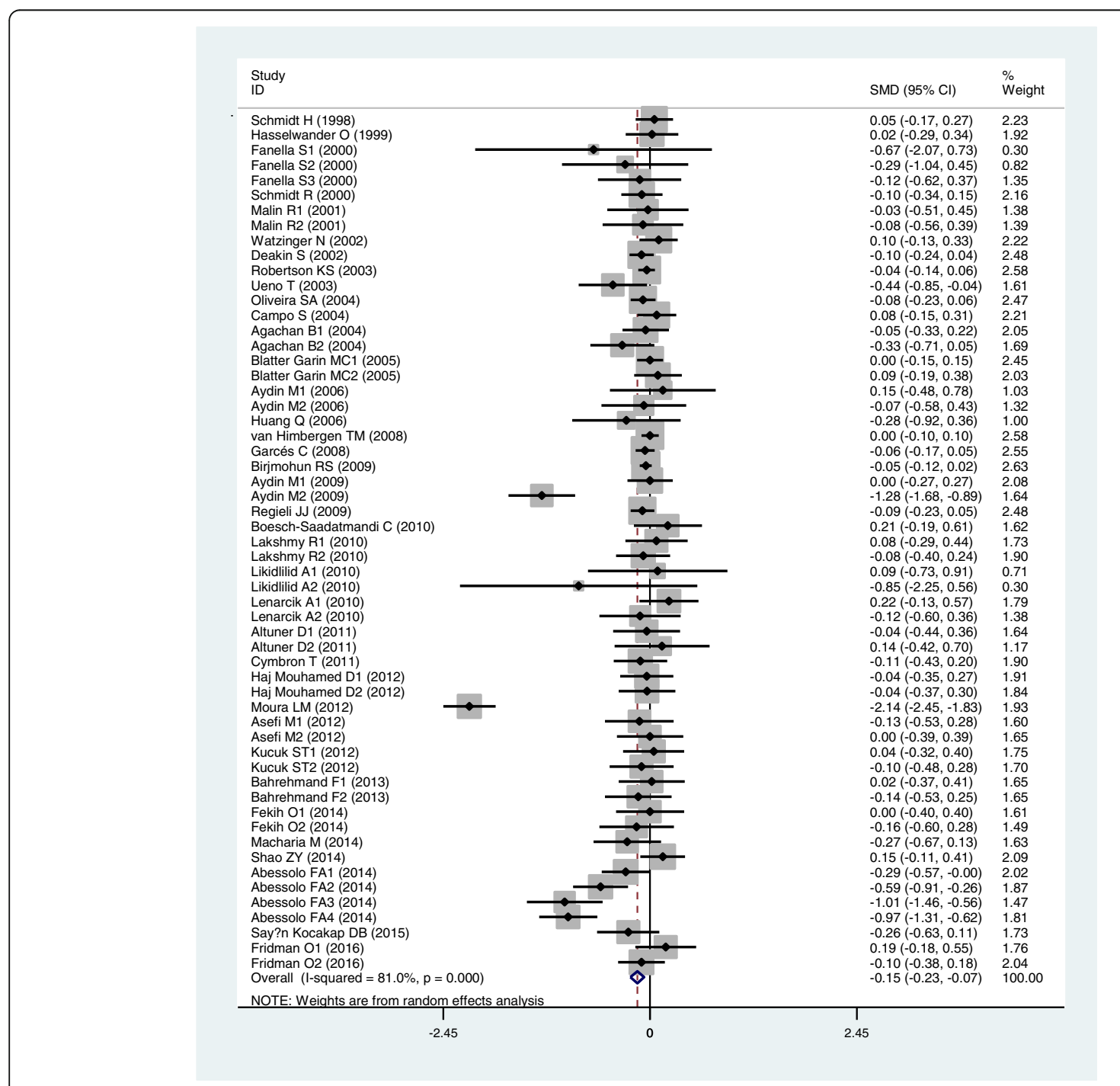

Fig. 2 Forest plot of the meta-analysis between the PON1 rs854560 polymorphism and plasma high-density lipoprotein cholesterol (HDL-C) levels 
by e-mail. All the information was extracted using a standardized data collection form.

\section{Data analysis}

All statistical tests were two-sided and conducted by the STATA software package (Version 10, Stata Corporation, College Station, TX). $P$-value smaller than 0.05 for any test or model was considered to be statistically significant. Standardized mean difference (SMD) with 95\% confidence interval (CI) was used for the meta-analysis. A fixed effect model (a Mantel-Haenszel method) was used to evaluate the results when heterogeneity among studies investigated by Cochrane $Q$ statistic was not significant $\left(\mathrm{I}^{2} \leq 50 \%, P>0.05\right)$. Otherwise, the random effect model (DerSimonian and Laird) was used [22]. Where there was significant heterogeneity among studies, we performed the Galbraith plot to detect potential sources of heterogeneity. Since the results of most of the included studies were reported in a dominant way $(\mathrm{LM}+\mathrm{MM}$ vs $\mathrm{LL})$, a dominant model was employed to ensure adequate statistical power. Subgroup analyses were performed by ethnicity, gender and health condition. The ethnic subgroup was defined as Caucasian, Asian, and subjects of other ethnic origins. Health condition subgroup was defined as CHD patients, type 2 diabetes mellitus (T2DM) patients and healthy/control subjects. When data were presented for more than one subpopulation (e.g., female or male subjects, the subjects with CHD or T2DM, the subjects from different ethnicities) in one article, each subpopulation was treated as a separate comparison. Hardy-Weinberg equilibrium (HWE) was assessed by Fisher's exact test and a $P$-value $<0.05$ was considered statistically significant. Possible publication bias was tested by Begg's funnel plots and Egger's test using $P<0.05$ to indicate the presence of potential publication bias.

\section{Result}

\section{Selection and characteristics of studies}

Initial search of the databases yielded 903 articles. Eight hundred thirty-four studies were excluded according to the titles and abstracts. Then full-text articles were retrieved and assessed on the basis of the inclusion criteria. Twenty-eight studies were ineligible for the following reasons: 21 studies presented data for other polymorphisms, 5 studies were based on pedigree analysis, and 2 studies had subjects overlapping with other publications. In the end, 41 studies were selected for this meta-analysis (Fig. 1). Out of them, 26 studies (34 comparisons) involved Caucasian subjects; three studies (three comparisons) involved Asian subjects; and 12 studies (24 comparisons) had to do with the subjects of other ethnic origins. Eight of the included studies were case-control studies, while the remaining 33 studies were cohort studies.

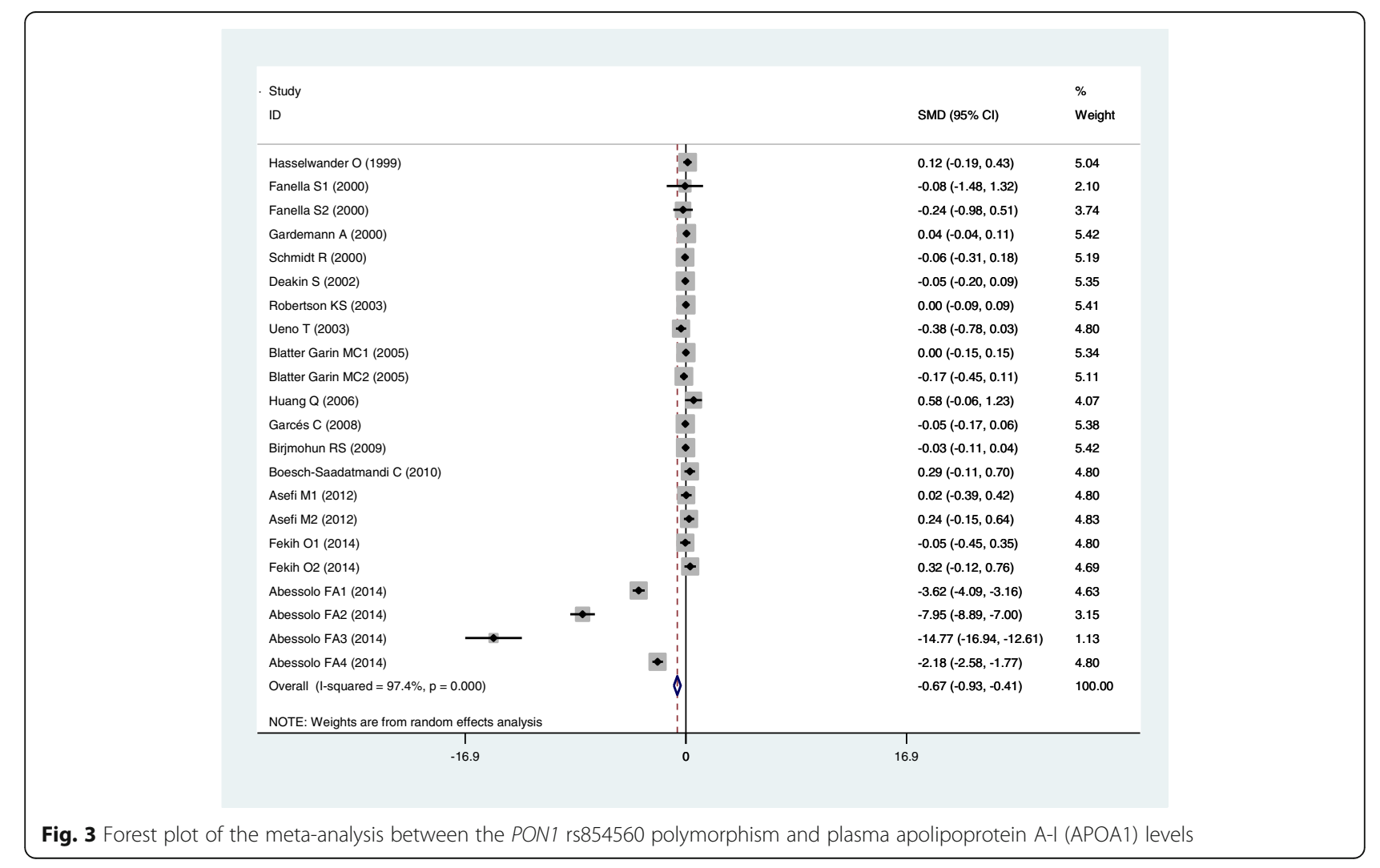


The references for the studies included in the present meta-analysis are listed in Additional file 1. The characteristics of the studies included in the lipid association analysis are summarized in Additional file 2: Table S1. The plasma lipid levels by the genotypes of the rs 854560 polymorphism are presented in Additional file 2: Table S2.

\section{Associations of the PON1 rs 854560 polymorphism with plasma lipid levels}

Results of the analyses on all comparisons showed that the $\mathrm{M}$ allele carriers had lower levels of HDL-C $(\mathrm{SMD}=-0.15$, 95\% CI $=-0.23--0.07, P<0.01)$ and APOA1 $(\mathrm{SMD}=-0.67$, 95\% CI $=-0.93-0.41, \quad \mathrm{P}<0.01) \quad$ than the non-carriers (Table 1, Figs. 2 and 3). When the analyses were limited to the studies in HWE, the significant associations between the rs854560 polymorphism and plasma levels of HDL-C (SMD $=-0.04,95 \% \mathrm{CI}=-0.07--0.01, P=0.05)$ and APOA1 (SMD $=-0.74,95 \% \mathrm{CI}=-1.03-0.46, P<0.01)$ were also detected (Table 1). No associations were found between the rs854560 polymorphism and plasma levels of TG $(\mathrm{SMD}=-0.01,95 \%$
$\mathrm{CI}=-0.07-0.06, P=0.87), \mathrm{TC}(\mathrm{SMD}=-0.05,95 \% \mathrm{CI}=-$ $0.11-0.02, P=0.15)$, and LDL-C $(\mathrm{SMD}=0.00,95 \% \mathrm{CI}=-$ 0.06-0.06, $P=0.91$ ) (Table 1, Figs. 4, 5 and 6).

From the subgroup analyses stratified by the characteristics of the subjects, significant associations of the rs854560 polymorphism with lower levels of HDL-C $(\mathrm{SMD}=-0.11, \quad 95 \% \quad \mathrm{CI}=-0.20--0.02, \quad P=0.02) \quad$ and higher levels of LDL-C (SMD $=0.06,95 \% \mathrm{CI}=0.01-0.12$, $P=0.03$ ) were detected in Caucasians. The rs 854560 polymorphism was significantly associated with lower levels of HDL-C (SMD $=-0.32,95 \% \mathrm{CI}=-0.52--0.13, P$ $<0.01)$ and APOA1 $(\mathrm{SMD}=-4.46, \quad 95 \% \quad \mathrm{CI}=-$ 6.69--2.24, $P<0.01)$ in the subjects of other ethnic origins. The rs854560 polymorphism was also significantly associated with higher levels of TG (SMD $=0.22,95 \%$ $\mathrm{CI}=0.01-0.41, P=0.05)$ in Asians. When health status was taken into account, the significant association of the rs854560 polymorphism with lower levels of HDL-C was detected in the T2DM patients, the healthy/control subjects and the case-control subjects (Table 1).

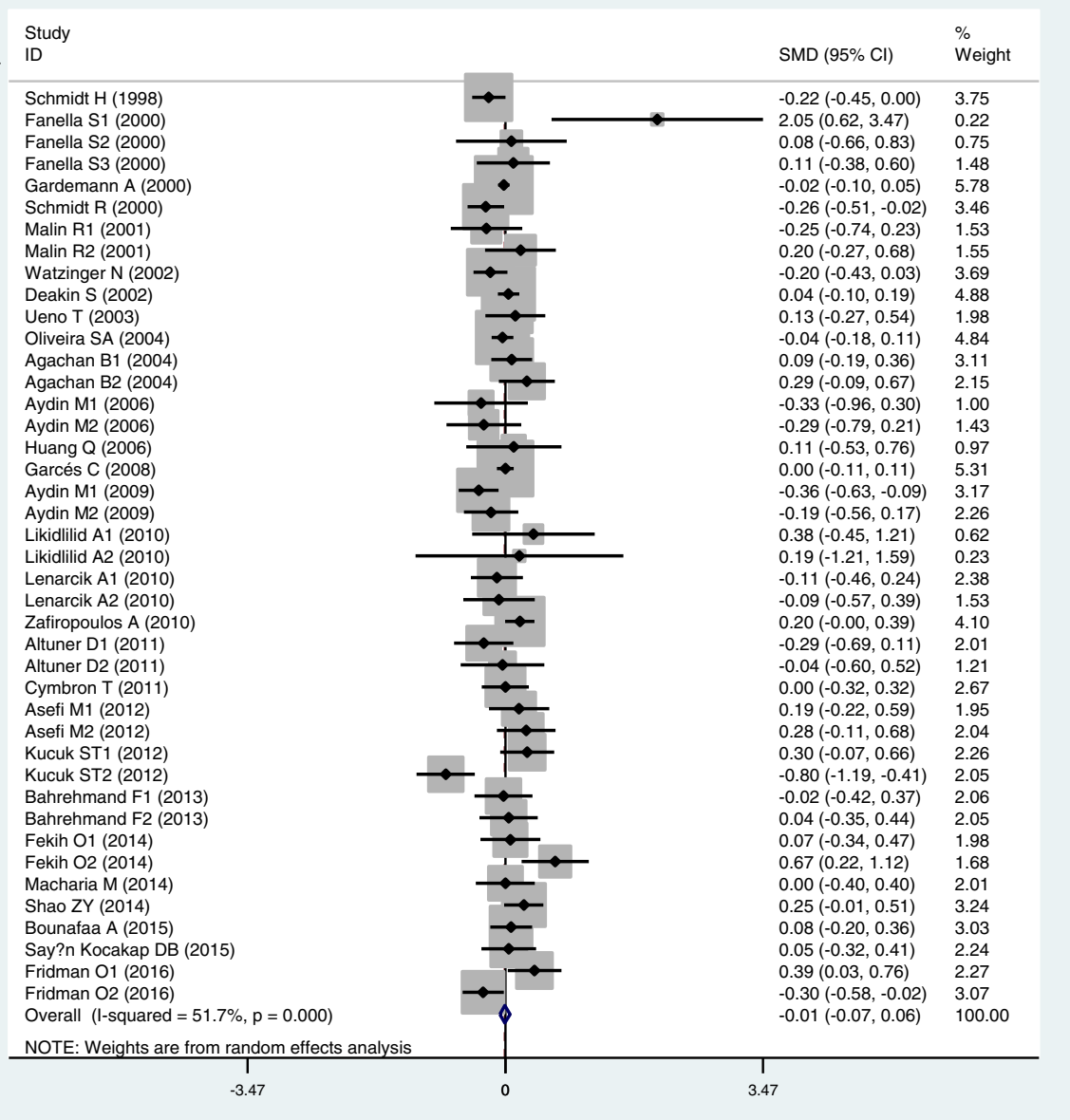

Fig. 4 Forest plot of the meta-analysis between the PON1 rs 854560 polymorphism and triglycerides (TG) levels 


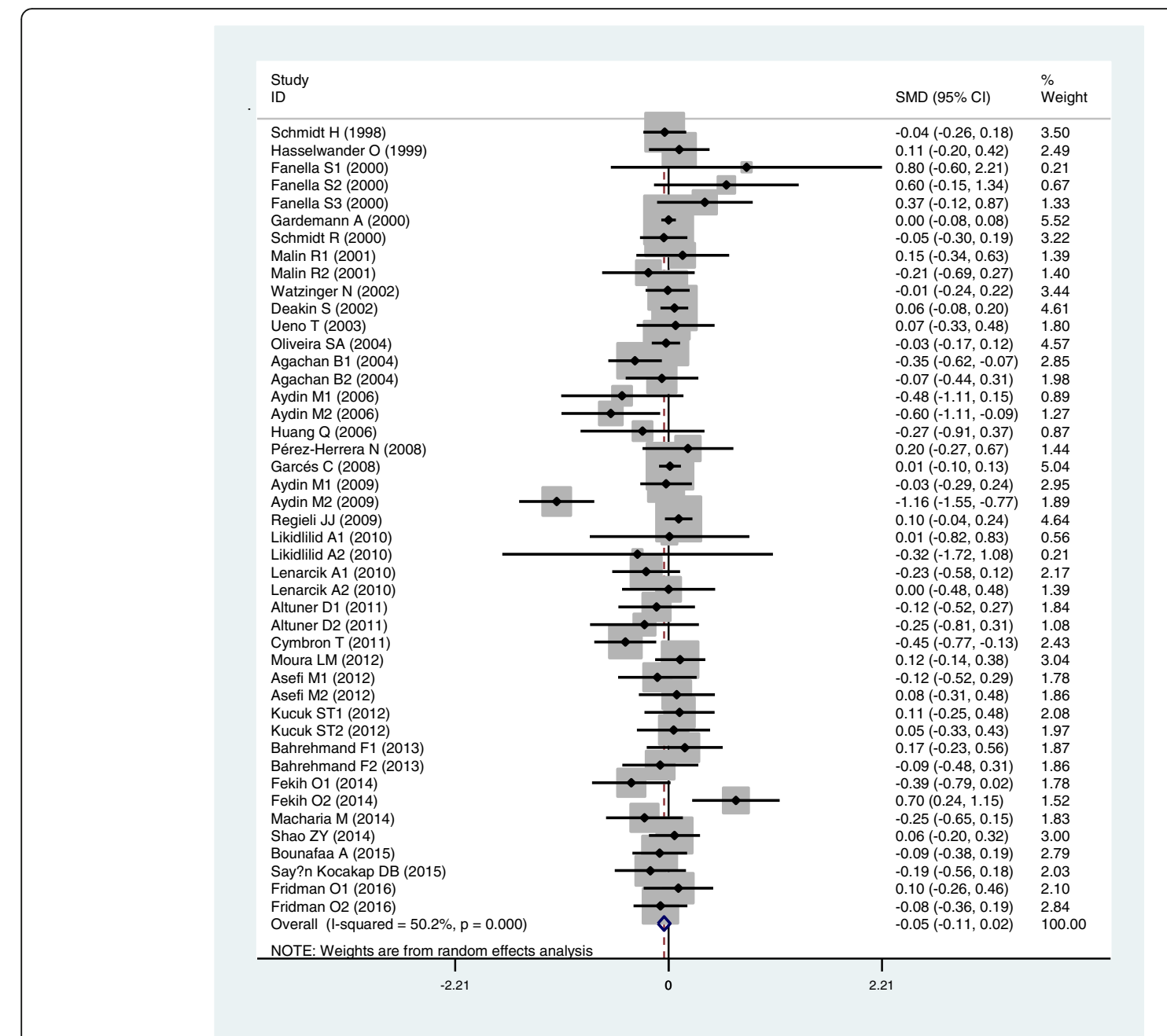

Fig. 5 Forest plot of the meta-analysis between the PON1 rs854560 polymorphism and plasma total cholesterol (TC) levels

\section{Evaluation of heterogeneity}

The heterogeneity among studies was significant for the five lipid variables (TG: $I^{2}=51.7 \%, P_{\text {heterogeneity }}<0.01$; TC: $I^{2}=$ $50.2 \%, P_{\text {heterogeneity }}<0.01$; LDL-C: $I^{2}=47.4 \%, P_{\text {heterogeneity }}<0.01$; HDL-C: $I^{2}=81.0 \%, P_{\text {heterogeneity }}<0.01$; APOA1: $I^{2}=97.4 \%, P_{\text {he- }}$ terogeneity $<0.01$ ). Six comparisons (Fanella S1 2000, Fekih O2 2014, Fridman O1 2016, Kucuk ST2 2012, Aydin M1 2009, Zafiropoulos A2 2010), 5 comparisons (Fekih O2 2014, Aydin M2 2009, Cymbron T 2011, Agachan B1 2004, Aydin M2 2006), 5 comparisons (Fekih O2 2014, Moura LM 2012, Pérez-Herrera N 2008, Aydin M2 2009, Agachan B1 2004), 4 comparisons (Moura LM 2012, Aydin M2 2009, Abessolo FA3 2014, Abessolo FA4 2014) and 4 comparisons (Abessolo FA1 2014, Abessolo FA2 2014, Abessolo FA3 2014, Abessolo FA4 2014) were identified as the main contributors to the heterogeneity for TG, TC, LDL-C, HDL-C and APOA1, respectively, by using Galbraith plots. The SMD values and $95 \%$ CIs of TG $\left(\mathrm{SMD}=-0.02,95 \% \mathrm{CI}=-0.06-0.02, P_{\text {Heterogeneity }}=\right.$ $\left.0.38, P_{S M D}=0.40\right)$, TC $(\mathrm{SMD}=-0.00,95 \% \mathrm{CI}=-0.04-0.04$, $\left.P_{\text {Heterogeneity }}=0.69, P_{S M D}=0.87\right), \mathrm{LDL}-\mathrm{C}(\mathrm{SMD}=0.01,95 \% \mathrm{CI}$ $\left.=-0.03-0.05, P_{\text {Heterogeneity }}=0.65, P_{S M D}=0.51\right)$ and HDL-C $\left(\mathrm{SMD}=-0.05, \quad 95 \% \mathrm{CI}=-0.08-0.02, \quad P_{\text {heterogeneity }}=0.83\right.$, $\left.P_{S M D}<0.01\right)$ did not change substantially after excluding these outlier comparisons. However, SMD value and $95 \% \mathrm{CI}$ of APOA1 $\left(\mathrm{SMD}=-0.01,95 \% \mathrm{CI}=-0.04-0.03, P_{\text {heterogeneity }}=\right.$ $\left.0.42, P_{S M D}=0.69\right)$ changed significantly after excluding the outlier comparisons.

\section{Publication bias test}

The Begg's funnel plot and Egger's test were used to evaluate the publication bias in the literature. In the present study, Begg's funnel plot showed no publication bias, and this was confirmed by Egger's test $(P=0.43$ for TG, 0.57 for TC, 0.56 for LDL-C, 0.98 for HDL-C, and 0.16 for APOA1).

\section{Discussion}

To the best of our knowledge, this is the first time that the associations of the PON1 rs854560 polymorphism with serum lipid levels are investigated. The present meta-analysis suggests that $M$ allele of the rs 854560 polymorphism is 


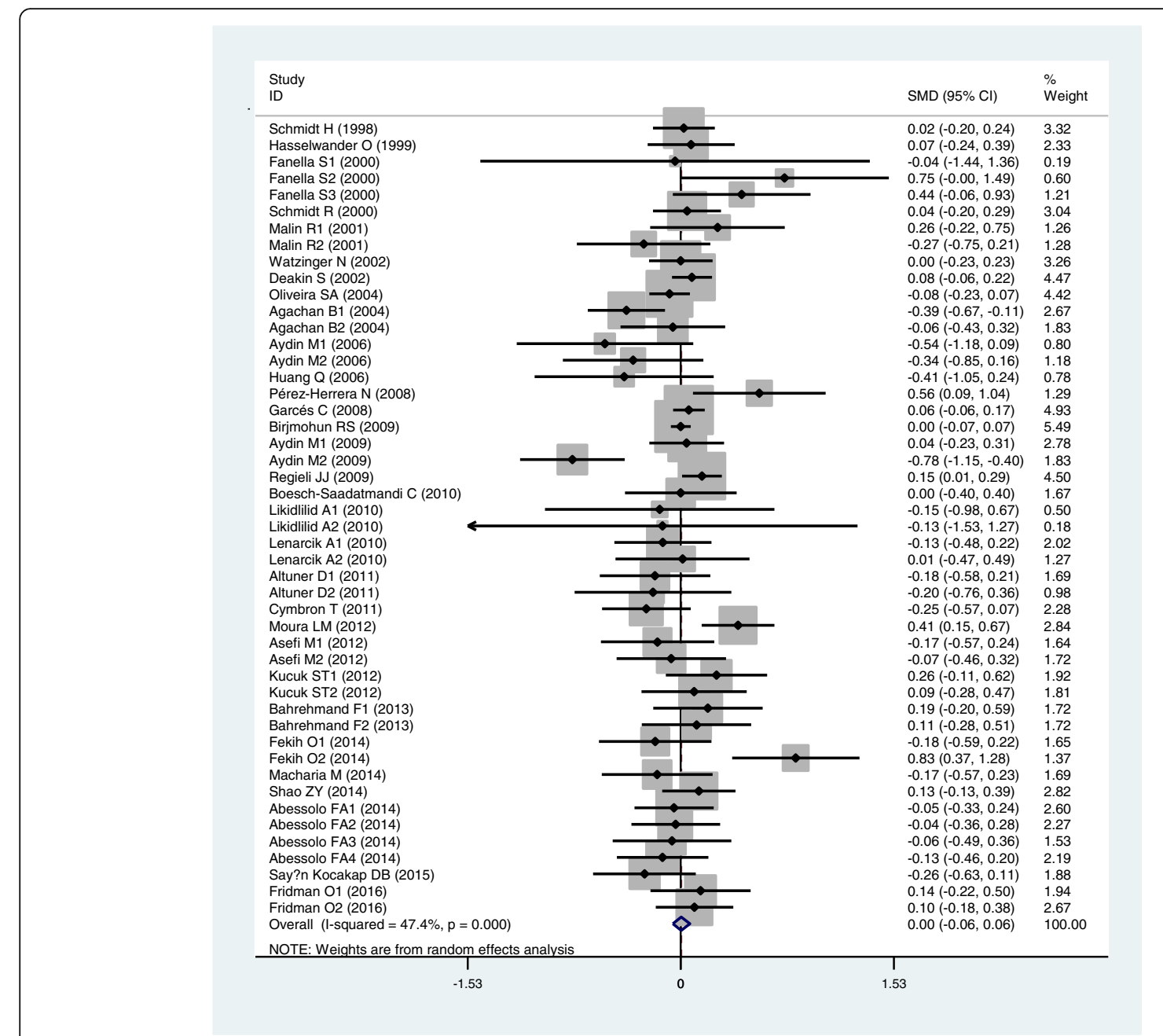

Fig. 6 Forest plot of the meta-analysis between the PON1 rs854560 polymorphism and plasma low-density lipoprotein cholesterol (LDL-C) levels

associated with lower levels of HDL-C and APOA1 in the total population. A number of case-control studies [7-9] demonstrated that $\mathrm{M}$ allele of the rs854560 polymorphism had a promoting role for CHD risk. In combination with our findings, it is possible that the association of rs 854560 polymorphism with a higher risk of CHD is mediated by the decreased levels of HDL-C and APOA1 caused by M allele of the rs854560 polymorphism.

Subgroup analyses by ethnicity, gender and health condition were performed since they might be important variables in determining associative risk with lipid levels. For example, the present meta-analysis indicated that ethnicity might modulate the associations of the rs854560 polymorphism with HDL-C levels since the strong significant associations only existed in Caucasians (Table 1). A recent meta-analysis [23] revealed that $M$ carriers of the rs 854560 polymorphism had a higher risk of CHD than the non-carriers in the populations involved Caucasians. In combination with our findings, it is possible that the association between $\mathrm{M}$ allele of the rs 854560 polymorphism and a higher risk of CHD in Caucasians was mediated by decreased HDL-C and APOA1 levels.

The PON1 rs854560 polymorphism may result in markedly reduced levels of HDL-C and APOA1 by affecting PON1 activity [11]. In 2014, Abessolo et al. performed a study on T2DM patients to assess the relationships between rs854560 polymorphism, PON1 activity and plasma lipid levels [16]. The results showed that the PON1 rs854560 polymorphism was significantly associated with decreased levels of HDL-C and APOA1 possibly via decreased serum PON1 activity. One possible explanation for this association is that the reduced PON1 enzyme activity might reduce the capacity of PON1-mediated inhibition of LDL oxidation [24, 25], which leads to increased levels of plasma ox-LDL (oxidized low-density lipoprotein) [26] and decreased levels of plasma HDL-C [27] and APOA1 [28]. This may also explain our findings. 
Smoking is an established risk factor for CHD as it increases oxidative stress in the development of atherosclerosis. By using logistic regression analysis, Watzinger et al. found that smoking was independently associated with CHD [29]. While Robertson et al. reported that the association between smoking and CHD risk was significantly modified by the rs854560polymorphism [30]. In 2008, Van et al. conducted a study on a middle-aged woman and found that PON1 activity was associated with CHD risk and the risk could be modified by smoking [31]. These results revealed that the PON1 rs854560 polymorphism might play an important role in predisposing the subjects to smoking-induced oxidative damage. However, more studies need to be performed to investigate the interaction between the PON1 rs854560 polymorphism and smoking.

Some limitations to the present meta-analysis should be noted. First, dyslipidemia is involved with a large number of genes. However, the interactions of the PON1 rs854560 polymorphism with other polymorphic loci on plasma lipid levels have not been investigated in this analysis due to lack of the original data from the included studies. Secondly, this meta-analysis only included the studies published in English and Chinese as it was very difficult to get full papers published in other languages.

\section{Conclusions}

The meta-analysis suggests that the PON1 rs854560 polymorphism is associated with a lower HDL-C level in Caucasians and the subjects of other ethnic origins. Further investigations of potential gene-gene and gene-environmental interactions are needed.

\section{Additional files}

Additional file 1: The reference list for the studies included in the present meta-analysis. (DOC $45 \mathrm{~kb}$ )

Additional file 2: Table S1. Characteristics of the individual studies included in the meta-analysis between the PON1 rs854560 polymorphism and plasma lipid levels; Table S2. Plasma lipid levels by the genotypes of the PON1 rs854560 polymorphism. (DOC $387 \mathrm{~kb}$ )

\section{Abbreviations \\ 95\% Cl: 95\% confidence interval; APOA1: apolipoprotein A-l; CHD: coronary heart disease; HDL-C: high-density lipoprotein cholesterol; HWE: Hardy- Weinberg equilibrium; LDL-C: low-density lipoprotein cholesterol; PON1: paraoxonase 1; RCT: reverse cholesterol transport; SMD: standardized mean difference; T2DM: type 2 diabetes mellitus; TC: total cholesterol; TG: triglyceride}

\section{Acknowledgements}

This research was supported by the grants from the Key Project of Education Department of Sichuan Province, P. R. China (17ZA0172) and the Cooperative Project on Scientific Research between Nanchong city and North Sichuan Medical College, P. R. China (NSMC20170403).

\section{Funding}

This research was supported by the grants from the Key Project of Education Department of Sichuan Province, P. R. China (17ZA0172) and the Cooperative Project on Scientific Research between Nanchong city and North Sichuan
Medical College, P. R. China (NSMC20170403). The funders had no role in study design, data collection and analysis, decision to publish, or preparation of the manuscript.

\section{Availability of data and materials}

All data generated or analysed during this study are included in this published article [and its supplementary information files].

\section{Authors' contributions}

YYS and ZL conceived of the study, participated in the design, and drafted the manuscript. SJL, IM and Md RK carried out the study searches and collected the data. ZL performed the statistical analyses. All authors read and approved the final manuscript.

\section{Ethics approval and consent to participate}

Not applicable.

\section{Consent for publication}

Not applicable.

\section{Competing interests}

The authors declare that they have no competing interests.

\section{Publisher's Note}

Springer Nature remains neutral with regard to jurisdictional claims in published maps and institutional affiliations.

\section{Author details}

'Department of Cardiology, Affiliated Hospital of North Sichuan Medical College, Nanchong 637000, People's Republic of China. ${ }^{2}$ School of Continuing Education, North Sichuan Medical College, Nanchong 637000, People's Republic of China. ${ }^{3}$ Department of Neurology, Taihe Hospital of Hubei University of Medicine, Shiyan, Hubei 442000, People's Republic of China. ${ }^{4}$ Department of Medical Biochemistry, and Nanchong Key Laboratory of Metabolic Drugs and Biological Products, North Sichuan Medical College, Nanchong 637000, People's Republic of China.

Received: 5 September 2018 Accepted: 21 November 2018 Published online: 03 December 2018

\section{References}

1. Mozaffarian D, Benjamin EJ, Go AS, Arnett DK, Blaha MJ, Cushman M, Das SR, de Ferranti S, Després JP, Fullerton HJ, Howard VJ, Huffman MD, Isasi CR, Jiménez MC, Judd SE, Kissela BM, Lichtman JH, Lisabeth LD, Liu S, Mackey RH, Magid DJ, McGuire DK, Mohler ER 3rd, Moy CS, Muntner P, Mussolino ME, Nasir K, Neumar RW, Nichol G, Palaniappan L, Pandey DK, Reeves MJ, Rodriguez CJ, Rosamond W, Sorlie PD, Stein J, Towfighi A, Turan TN, Virani SS, Woo D, Yeh RW, Turner MB. Executive summary: heart disease and stroke statistics--2016 update: a report from the American Heart Association. Circulation. 2016;133:447-54

2. Yusuf S, Hawken S, Ounpuu S, Dans T, Avezum A, Lanas F, McQueen M, Budaj A, Pais P, Varigos J, Lisheng L. Effect of potentially modifiable risk factors associated with myocardial infarction in 52 countries (the INTERHEART study): case-control study. Lancet. 2004;364:937-52.

3. Annema W, Tietge UJ. Regulation of reverse cholesterol transport - a comprehensive appraisal of available animal studies. Nutr Metab (Lond). 2012;9:25.

4. Akbas HS, Basyigit S, Suleymanlar I, Kemaloglu D, Koc S, Davran F, Demir I, Suleymanlar G. The assessment of carotid intimamedia thickness and serum paraoxonase-1 activity inHelicobacter pylori positive subjects. Lipids Health Dis. 2010;9:92.

5. Deakin S, Moren X, James RW. HDL oxidation compromises its influence on paraoxonase-1 secretion and its capacity to modulate enzyme activity. Arterioscler Thromb Vasc Biol. 2007;27:1146-52.

6. Rosenblat M, Gaidukov L, Khersonsky O, Vaya J, Oren R, Tawfik DS, Aviram $M$. The catalytic histidine dyad of high density lipoprotein-associated serum paraoxonase-1 (PON1) is essential for PON1-mediated inhibition of low density lipoprotein oxidation and stimulation of macrophage cholesterol efflux. J Biol Chem. 2006;281:7657-65.

7. Likidlilid A, Akrawinthawong K, Poldee S, Sriratanasathavorn C. Paraoxonase 1 polymorphisms as the risk factor of coronary heart disease in a Thai population. Acta Cardiol. 2010;65:681-91. 
8. Bounafaa A, Berrougui H, Ghalim N, Nasser B, Bagri A, Moujahid A, lkhlef S, Camponova P, Yamoul N, Simo OK, Essamadi A, Khalil A. Association between Paraoxonase 1 (PON1) polymorphisms and the risk of acute coronary syndrome in a north African population. PLoS One. 2015;10:e0133719.

9. Sayın Kocakap DB, Doğru MT, Şimşek V, Çabuk F, Yıldırım N, Çelik Y, Alyılmaz Bekmez S, Erdem S. The association of paraoxonase 1 gene L55M polymorphism with the extent and severity of coronary artery disease in the Turkish population and its dependence on gender. Anatol J Cardiol. 2016;16:175-82.

10. Fekih O, Triki S, Hellara I, Neffati F, Rejeb J, Ommezzine A, Chouchane S, Guediche MN, Bouslama A, Najjar MF. Can paraoxonase 1 polymorphisms (L55 M and Q192 R) protect children with type 1 diabetes against lipid abnormalities? J Clin Lipidol. 2014;8:249-55.

11. Fridman O, Gariglio L, Riviere S, Porcile R, Fuchs A, Potenzoni M. Paraoxonase 1 gene polymorphisms and enzyme activities in coronary artery disease and its relationship to serum lipids and glycemia. Arch Cardiol Mex. 2016;86:350-7.

12. Shao ZY, Li JR, Wang XD. Analysis of paraoxonase 1 gene polymorphisms in type 2 diabetic patients with coronary artery disease. Chin I Cardiovasc Med. 2014;19:426-9.

13. Fanella S, Harris SB, Young TK, Hanley AJ, Zinman B, Connelly PW, Hegele RA. Association between PON1 L/M55 polymorphism and plasma lipoproteins in two Canadian aboriginal populations. Clin Chem Lab Med. 2000;38:413-20.

14. Kucuk ST, Ademoglu E, Turkoglu UM, Bilge AK. Distribution of PON L/M55 and Q/R192 genotypes in Turkish patients with Angiographically-defined coronary artery disease: effects on serum lipids. Turkiye Klinikleri. J Med Sci. 2013;33:769-76.

15. Bahrehmand F, Vaisi-Raygani A, Ahmadi R, Kiani A, Rahimi Z, Tavilani H, Pourmotabbed T. Paraoxonase (PON1) 55 polymorphism and association with systemic lupus erythematosus. Iran J Allergy Asthma Immunol. 2013;12:211-9.

16. Abessolo FA, Bruno MJ, N'Negue MA, Yangou M, Ngoumilama E. Enzymatic and genetic polymorphisms of paraoxonase-1 in the Gabonese population: the relation to lipid parameters in patients with diabetes. J Endocrinol Metab Diabetes. 2012;17:92-9.

17. Asefi M, Vaisi-Raygani A, Bahrehmand F, Kiani A, Rahimi Z, Nomani $H_{\text {, }}$ Ebrahimi A, Tavilani H, Pourmotabbed T. Paraoxonase 1 (PON1) 55 polymorphism, lipid profiles and psoriasis. Br J Dermatol. 2012;167:1279-86.

18. Garcés C, López-Simón L, Rubio R, Benavente M, Cano B, Ortega H, de Oya M. High-density lipoprotein cholesterol and paraoxonase 1 (PON1) genetics and serum PON1 activity in prepubertal children in Spain. Clin Chem Lab Med. 2008:46:809-13.

19. Huang Q, Liu YH, Yang QD, Xiao B, Ge L, Zhang N, Xia J, Zhang L, Liu ZJ. Humann serum paraoxonase gene polymorphisms, Q192R and L55M, are not associated with the risk of cerebral infarction in Chinese Han population. Neurol Res. 2006;28:549-54.

20. Schmidt R, Schmidt H, Fazekas F, Kapeller P, Roob G, Lechner A, Kostner GM, Hartung HP. MRI cerebral white matter lesions and paraoxonase PON1 polymorphisms: three-year follow-up of the austrian stroke prevention study. Arterioscler Thromb Vasc Biol. 2000;20:1811-6.

21. Deakin S, Leviev I, Nicaud V, Brulhart Meynet MC, Tiret L, James RW, European atherosclerosis risk Study Group. Paraoxonase-1 L55M polymorphism is associated with an abnormal oral glucose tolerance test and differentiates high risk coronary disease families. J Clin Endocrinol Metab. 2002;87:1268-73.

22. Dersimonian R, Kacker R. Random-effects model for meta-analysis of clinical trials: an update. Contemp Clin Trials. 2007;28:105-14.

23. Hernández-Díaz Y, Tovilla-Zárate CA, Juárez-Rojop IE, González-Castro TB, Rodríguez-Pérez C, López-Narváez ML, Rodríguez-Pérez JM, Cámara-Álvarez JF. Effects of paraoxonase 1 gene polymorphisms on heart diseases: systematic review and meta-analysis of 64 case-control studies. Medicine (Baltimore). 2016;95:e5298.

24. Ribeiro S, do Sameiro Faria M, Mascarenhas-Melo F, Freitas I, Mendonça MI, Nascimento H, Rocha-Pereira P, Miranda V, Mendonça D, Quintanilha A, Belo L, Costa E, Reis F, Santos-Silva A. Main determinants of PON1 activity in hemodialysis patients. Am J Nephrol. 2012;36:317-23.

25. Nus M, Frances F, Sánchez-Montero JM, Corella D, Sánchez-Muniz FJ. WeW44:4 Arylesterase activity and HDL-cholesterol levels are dependent on the PON 55M and PON 192R polymorphisms. Atheroscler Suppl. 2006;7:333.

26. Jiang XL, Li M, Zhou JG, Yang QB, Du LJ, Du J. Plasma paraoxonase-1, oxidized low-density lipoprotein and lipid peroxidation levels in gout patients. Cell Biochem Biophys. 2011;61:461-6.
27. Singh S, Venketesh S, Verma JS, Verma M, Lellamma CO, Goel RC. Paraoxonase (PON1) activity in North West Indian Punjabis with coronary artery disease \& amp; type 2 diabetes mellitus. Indian J Med Res. 2007;125:783-7.

28. Ayoglu OB, Ekmekci OB, Ekmekci H, Ayaoglu RU, Belce A. Paraoxonase Activity and Oxidized LDL levels as cardiovascular risk factors in patients with coronary artery disease. Istanbul Med J. 2013;14:69-75.

29. Watzinger N, Schmidt H, Schumacher M, Schmidt R, Eber B, Fruhwald FM, Zweiker R, Kostner GM, Klein W. Human paraoxonase 1 gene polymorphisms and the risk of coronary heart disease: a community-based study. Cardiology. 2002;98:116-22.

30. Robertson KS, Hawe E, Miller GJ, Talmud PJ, Humphries SE, Northwick Park heart study II. Human paraoxonase gene cluster polymorphisms as predictors of coronary heart disease risk in the prospective Northwick Park heart study II. Biochim Biophys Acta. 2003;1639:203-12.

31. van Himbergen TM, van der Schouw YT, Voorbij HA, van Tits LJ, Stalenhoef AF, Peeters PH, Roest M, van Himbergen TM, van der Schouw YT, Voorbij HA, van Tits LJ, Stalenhoef AF, Peeters PH, Roest M. Paraoxonase (PON1) and the risk for coronary heart disease and myocardial infarction in a general population of Dutch women. Atherosclerosis. 2008;199:408-14.

\section{Ready to submit your research? Choose BMC and benefit from:}

- fast, convenient online submission

- thorough peer review by experienced researchers in your field

- rapid publication on acceptance

- support for research data, including large and complex data types

- gold Open Access which fosters wider collaboration and increased citations

- maximum visibility for your research: over $100 \mathrm{M}$ website views per year

At BMC, research is always in progress.

Learn more biomedcentral.com/submissions 